\title{
Assessing the Psychometric Properties of Both a Global and a Domain-Specific Perceived Quality of Life Measure When Used with Youth Who Have Chronic Conditions
}

\author{
Janette McDougall • Virginia Wright • Megan Nichols • \\ Linda Miller
}

Accepted: 6 November 2012/Published online: 11 November 2012

(C) Springer Science+Business Media Dordrecht 2012

\begin{abstract}
The purpose of this paper was to assess the psychometric properties of the Students' Life Satisfaction Scale (SLSS) and the Brief Multidimensional Students' Life Satisfaction Scale (BMSLSS) when used with youth who have chronic conditions. Baseline data from a longitudinal study examining predictors of changes in perceived quality of life (PQOL) for youth with chronic conditions were used. SLSS and BMSLSS data were collected on over 400 youth aged 11-17 using youth self-report and parent proxy-report versions. Internal consistency, convergent validity, and factor structure were examined for both versions. Extent of agreement and magnitude of differences between youth and parent report were evaluated. Finally, gender, age, and condition group differences in youth report scores were examined for the SLSS and BMSLSS. Strong internal consistency was demonstrated for the youth and parent reports of both measures. As with normative samples, a single factor structure was found for youth and parent reports of the BMSLSS. However, both youth and parent reports of the SLSS had a two-factor structure: one consisting of five positively worded items, and the other, two negatively worded items. Youth reported their PQOL to be significantly higher than did their parents. Significant differences in PQOL scores for the youth report were not found by age, gender, or conditions. Findings show that, from a psychometric standpoint, the BMSLSS (both youth and parent report) is a promising measure of PQOL for use in population-based research with youth who have chronic conditions. The SLSS may need to be revised to exclude negative items when used with this population of youth.
\end{abstract}

Keywords Quality of life · Life satisfaction - Adolescence - Chronic conditions · Measurement

J. McDougall $(\bowtie) \cdot$ M. Nichols

Thames Valley Children's Centre, 779 Base Line Road East, London, ON N6C 5Y6, Canada

e-mail: janette.mcdougall@tvcc.on.ca

V. Wright

Bloorview Research Institute, 150 Kilgour Road, Toronto, ON M4G 1R8, Canada

L. Miller

School of Graduate and Postdoctoral Studies, Western University, London, ON N6A 5B7, Canada 


\section{Introduction}

The concept of quality of life (QOL) has increasingly been a focus of interest in health and rehabilitation research throughout the past three decades (Moons et al. 2006). In these areas of research, QOL has often been evaluated in terms of concepts like physical symptoms, functional status, or general health. However, many researchers suggest that health-related QOL (HQOL) should not be differentiated from a broader notion of QOL (Davis et al. 2006; Wallander et al. 2001). That is, QOL does not depend primarily on a person's health status; rather, health status is only one of several factors influencing QOL for all people (King et al. 2005; McDougall et al. 2010). Indeed, several concept analyses of QOL suggest that the concept should be defined in terms of overall life satisfaction or perceived QOL (PQOL), as opposed to such concepts as normal functioning, social utility, happiness, etc. (Ferrans 1996; Moons et al. 2006; Zhan 1992).

\subsection{PQOL Neglected in Research for Children and Youth with Chronic Conditions}

While early population-based PQOL research focused for the most part on adults, during the past two decades, heightened attention has been paid to the correlates and consequences of individual differences in overall life satisfaction or global PQOL among children and adolescents (Gilman and Huebner 2003). Indeed, studies that have taken this approach have found significant personal, interpersonal, and environmental factors related to PQOL for children and youth in the general population, including emotional and behavioral functioning, physical activity, relationships with parents and peers, social participation, and neighborhood quality (Fogle et al. 2002; Gilman 2001; Gilman and Huebner 2003; Huebner et al. 2004, 2007; Proctor et al. 2009a; Valois et al. 2001).

Such research demonstrates that the utilization of measures of life satisfaction can contribute to an understanding of what youth feel is most important to their lives. Similar evaluations of life satisfaction among children and youth with chronic conditions has the potential to yield valuable information for researchers, health and education professionals, and policy makers, in addition to others who are working with this particular population of young people (McCullough and Huebner 2003; Vassar and Hale 2007).

A recent review (Proctor et al. 2009b) to determine all measures available for assessing life satisfaction for youth identified eight published instruments: the Students' Life Satisfaction Scale (SLSS) (Huebner 1991a); the Satisfaction with Life Scale (Diener et al. 1985); the Perceived Life Satisfaction Scale (Smith et al. 1987); Multidimensional Students' Life Satisfaction Scale (Huebner 1994); Multidimensional Students' Life Satisfaction Scale-Adolescent (Gilligan and Huebner 2007); the Brief Multidimensional Students' Life Satisfaction Scale (BMSLSS) (Seligson et al. 2003); the Extended Satisfaction with Life Scale (Alfonso et al. 1996); and the Comprehensive Quality of Life Scale (Cummins et al. 1994). The review reports the reliability and validity evaluations that have been conducted for these measures.

Few of the life satisfaction measures reviewed have been used with or tested with youth who have chronic conditions. Indeed, when the construct of QOL has been studied using samples of youth with chronic conditions, a health-related approach has almost always been employed, with life satisfaction being virtually ignored (Proctor et al. 2009a). For example, both Eiser and Morse (2001) and Davis et al. (2006), in their reviews of available measures for assessing QOL for children with chronic conditions, found that the vast majority of instruments used have a primary focus on health-related concepts [e.g., the 
Child Health Questionnaire (Graham et al. 1997), the Functional Status II (R) (Stein and Jessop 1990), and the Health Utilities Index Mark 2 and 3 (Feeny et al. 1995)].

Existing measures of life satisfaction need to be tested with youth who have chronic conditions so that studies seeking to examine this concept among these young people, and the factors related to it, have reliable and valid measures to use (Brantley et al. 2002). The psychometric properties of subjective QOL measures with children and youth from the general population cannot be assumed to generalize to those with chronic conditions (Brantley et al. 2002).

\subsection{Purpose of Paper}

This paper is the first to provide a comprehensive assessment of psychometric properties for two brief measures of life satisfaction when used with youth who have chronic conditions: the SLSS (Huebner 1991a), a seven-item global measure of overall satisfaction with life quality that provides a single total score, and the BMSLSS (Seligson et al. 2003), a five-item general measure that provides a profile of life satisfaction across multiple life domains as well as a combined total score (for a preliminary report in abstract form, see McDougall et al. 2012). Of all life satisfaction measures available, these measures are thought to be the most appropriate for the assessment of large samples where instruments need to be brief (Gilman and Huebner 2003). The primary purpose of this study is to assess whether the SLSS and the BMSLSS can be used reliably and validly in population-based research studies to assess the perceived satisfaction with life quality of children and youth with chronic conditions.

Both of these PQOL measures have been validated on numerous samples of children and youth in the general population aged 8-18 in a number of different countries, including the US and Canada, and have documented good to excellent reliability (high internal consistency with adolescent samples [alphas ranging from 0.82 (Terry and Huebner 1995) to 0.86 (Dew and Huebner 1994) for the SLSS, and from 0.75 (Seligson et al. 2003) to 0.85 (Huebner et al. 2000) for the BMSLSS across samples] and test-retest reliability [0.91 for the BMSLSS (Funk et al. 2006) and 0.74 for the SLSS (Huebner, 1991b) for a one to twoweek interval)]. Evidence exists of the construct and convergent validity for both the SLSS (e.g., Dew and Huebner 1994; Gilman and Huebner 1997; Huebner and Alderman 1993) and the BMSLSS (e.g., Funk et al. 2006; Seligson et al. 2003, 2005). Factor analyses have consistently supported a one-factor structure for both measures (e.g., Dew and Huebner 1994; Funk et al. 2006; Gilman and Huebner 1997; Seligson et al. 2005; Zullig et al. 2005). Scores of neither instrument have been found to be related to demographic variables, such as age and gender (e.g., Dew and Huebner 1994; Funk et al. 2006; Gilman and Huebner 1997; Huebner and Alderman 1993; Huebner et al. 2000; Seligson et al. 2003).

A proper assessment of child well being should take into account children's own perspectives (Fernandes et al. 2012). At the same time, the perspectives of both children and parents are important for making both intervention-related and policy decisions (Eiser and Morse 2001; Helders 2001; Livingstone et al. 2007) since children and parents are likely to place different values on life states (Feldman et al. 2000). In order to compare parents' perceptions of youths' PQOL, permission was received from the original authors of the SLSS and the BMSLSS to adapt them to become parent reports as well. This adaptation permitted examination and comparison of youth self report and parent proxy report of life satisfaction on each measure.

A non-categorical approach to illness was adopted for this study, combining youth with different chronic health conditions into the total group sample (Stein and Jessop 1984). 
Many studies support combining apparently distinct chronic conditions for populationbased research because there is great commonality in their psychological and psychosocial implications (Gortmaker et al. 1990; Law et al. 2004; Pless and Perrin 1985; Stein and Jessop 1984; Wallander and Varni 1989). Researchers have found as much variation in disease severity within condition categories as they have between categories (Stein and Jessop 1984).

\section{Method}

\subsection{Participants}

Baseline data from a longitudinal study examining predictors of changes in PQOL for a random sample of 439 youth with chronic conditions, ages 11-17 years, were used to assess psychometric properties of youth and parent reports of the SLSS and the BMSLSS. For each youth enrolled in the study, one parent (most often the mother) also participated. A prospective cohort design (Bijleveld et al. 1998) is being used for the PQOL study, with a 3-year follow-up of each participant.

This study focuses on youth with the kinds of physical, developmental, and communicative chronic conditions for which rehabilitation services are typically provided in children's treatment centers. Youth were recruited from eight children's treatment centers. Study youth had any one or more of the following chronic conditions: cerebral palsy, spina bifida, autism spectrum disorder, acquired brain injury, developmental delay, cleft lip and/ or palate, Down syndrome, arthritis, communication disorder, amputation, or any other non-progressive muscular or central nervous system disorder. Youth with any progressive health condition, where life expectancy is not anticipated to extend beyond young adulthood (e.g., muscular dystrophy) were not included in the study. A significantly decreased life span may have a profound effect on youths' PQOL.

To be eligible for the study, youth also needed to be cognitively able to independently understand and answer the study questionnaires with the guidance of a study interviewer (i.e., a trained health professional). Parents assessed youths' cognitive ability prior to entrance into the study. The parent was provided with a series of sample questionnaire items and then made the determination whether their child would be able to respond accurately to them. Study interviewers also made a clinical judgement of the youths' cognitive ability to participate in the study following the baseline interview. If a youth was deemed not able to participate, they were excluded from the study, and their data was not used.

\subsection{Measures}

Questionnaires measuring youths' PQOL and the hypothesized predictors of changes in quality of life are administered to youth and their parents shortly at study entry and every 12 months over the course of 3 years. At the time of writing this paper, the baseline interviews have been completed, and investigators are continuing to collect data for the additional time points.

The youth and parent report versions of the SLSS contain seven context-free items each that are rated using a six-point scale: $(6=$ strongly agree; $5=$ moderately agree; $4=$ mildly agree; $3=$ mildly disagree; $2=$ moderately disagree; $1=$ strongly agree) . Five items are positively worded (e.g., my life is going well). Two items are negatively 
worded (e.g., I would like to change things in my life) and require reverse coding in the scoring.

The BMSLSS youth and parent report versions contain five items each that inquire about satisfaction with various life domains (i.e., family, friends, school, self, living environment). Items are rated using a seven-point scale: $(7=$ delighted; $6=$ pleased; $5=$ mostly satisfied; $4=$ mixed; $3=$ mostly dissatisfied; $2=$ unhappy; $1=$ terrible).

\subsection{Procedures}

Baseline data collection occurred either in a private office at the youth's treatment centre or in the privacy of the youth's home. The parent and youth made the choice of location. Interviewers obtained written informed consent in person from youth and parents just before conducting the baseline assessment. After a standardized introduction to the questionnaire, each youth took part in a face-to-face interview (30-60 min) with additional support as required from the study interviewer (e.g., further explanation of questions). The parent questionnaire (each 30-60 min) was self-completed and was done independently in a separate room at the same time as the youth interview. The youth and parent were not given access to each other's responses (see McDougall et al. 2011 for greater detail about the original study).

\subsection{Data Analyses}

Descriptive analyses of the SLSS and BMSLSS youth report were conducted. Independent $t$ tests or analyses of variance were also carried out to determine mean differences in SLSS and BMSLSS total scores for the youth report in relation to gender, age, and chronic condition groups. Cronbach's alpha was computed to examine the internal consistency of the youth and parent report versions of the SLSS and the BMSLSS. Pearson correlation coefficients were estimated between SLSS scores and BMSLSS scores within the youth and parent report versions to assess convergent validity of the two measures. Exploratory principal components factor analyses with varimax rotation were used to examine the structure of the youth and parent report versions for both measures. Intraclass correlation coefficients (ICC) (two way random effects models) were estimated to evaluate youthparent (inter-rater) agreement, and paired $t$ tests were conducted to assess mean differences between the youth and parent reports on the SLSS and BMSLSS total scores and individual item scores. To adjust for multiple testing, $p$ values were set at 0.01. SPSS Version 19 was used for all data analyses.

\section{Results}

\subsection{Sample Characteristics}

Full SLSS and BMSLSS youth report data were available for 428 and 434 of the 439 youth in the original sample, respectively. The mean age of youth was 14 years $(\mathrm{SD}=2.2)$. There were slightly more males $(56 \%)$ than females. Cerebral palsy was the largest condition group (35\%), followed by acquired brain injury (14\%) (see Tables 1, 2). Parents' mean age was 45 years $(\mathrm{SD}=6.5)$, with more female $(88 \%)$ than male parents participating. Eighty-three percent of parent respondents were birth mothers to the youth, 
$11 \%$ were birth fathers, $4 \%$ were adoptive mothers, and $2 \%$ were another type of relationship (e.g., step father, grandmother). English was spoken in $90 \%$ of families' homes, French in $2 \%$, and various other languages in $8 \%$ of homes.

\subsection{Results from Descriptive and Comparative Analyses of the SLSS and BMSLSS Youth Report}

SLSS youth total scores varied from 10.0 to 42.0 out of a possible 42.0 points, while BMSLSS youth total scores varied from 11.0 to 35.0 out of a possible 35.0 points. The mean score for the SLSS was 32.83 (SD =6.57), and the median score was 34.00; the mean score for the BMSLSS was 29.80 ( $\mathrm{SD}=4.25)$, and the median score was 31.00 . No floor effects (i.e., lowest possible scores) were found. Ceiling effects (i.e., perfect scores) for the SLSS were found for $7 \%(n=30)$ of the sample, and for the BMSLSS, $11 \%$ $(\mathrm{n}=35)$ of the sample. Tables 1 and 2 provide SLSS and BMSLSS score descriptive statistics for age, gender, and condition groups. No significant differences in either SLSS or BMSLSS youth report scores existed for age $(F=1.07 ; p<0.38 ; F=0.72 ; p<0.63)$ or gender at $p<0.01$ ( $t=2.26 ; p<0.02 ; t=0.88 ; p<0.38)$, respectively. Likewise, no significant differences in BMSLSS or SLSS youth report scores existed for condition groups at $p<0.01$ ( $F=1.99 ; p<0.06 ; F=2.08 ; p<0.05)$. However, since differences approached traditional significance in SLSS youth report scores for condition groups, post hoc analyses (Tukey tests) were used to explore where the differences lied between each of

Table 1 Descriptive statistics: sample characteristics and SLSS scores for youth report

\begin{tabular}{|c|c|c|c|}
\hline \multirow[t]{2}{*}{ Characteristics } & \multicolumn{3}{|l|}{ SLSS scores } \\
\hline & $n(\%)$ & $M(\mathrm{SD})$ & Minimum-Maximum \\
\hline \multicolumn{4}{|l|}{ Age } \\
\hline 11 & $101(23 \%)$ & $33.44(6.26)$ & $11-42$ \\
\hline 12 & $58(14 \%)$ & $33.17(6.51)$ & $10-42$ \\
\hline 13 & $55(13 \%)$ & $34.07(6.36)$ & $17-42$ \\
\hline 14 & $46(11 \%)$ & $32.67(7.38)$ & $14-42$ \\
\hline 15 & $43(10 \%)$ & $32.07(5.63)$ & $20-42$ \\
\hline 16 & $58(13 \%)$ & $32.47(7.10)$ & $14-42$ \\
\hline 17 & $67(16 \%)$ & $31.52(6.73)$ & $14-42$ \\
\hline \multicolumn{4}{|l|}{ Gender } \\
\hline Female & $190(44 \%)$ & $32.03(6.85)$ & $11-42$ \\
\hline Male & $238(56 \%)$ & $33.47(6.28)$ & $10-42$ \\
\hline \multicolumn{4}{|l|}{ Condition } \\
\hline Cerebral palsy & $150(35 \%)$ & $33.06(6.64)$ & $13-42$ \\
\hline Acquired brain injury & $59(14 \%)$ & $32.00(7.43)$ & $10-42$ \\
\hline Communication/cleft lip-palate & $40(11 \%)$ & $35.03(6.05)$ & $16-42$ \\
\hline Spina bifida & $36(8 \%)$ & $31.30(6.49)$ & $16-42$ \\
\hline Autism spectrum disorder & $35(7 \%)$ & $31.57(6.26)$ & $11-42$ \\
\hline Developmental delay & $28(6 \%)$ & $34.25(4.71)$ & $24-42$ \\
\hline Amputation & $18(4 \%)$ & $35.22(3.65)$ & $26-42$ \\
\hline Other & $62(15 \%)$ & $31.91(7.02)$ & $14-42$ \\
\hline
\end{tabular}

Sample $(n=428)$ 
Table 2 Descriptive statistics: sample characteristics and BMSLSS scores for youth report

\begin{tabular}{|c|c|c|c|}
\hline \multirow[t]{2}{*}{ Characteristics } & \multicolumn{3}{|c|}{ BMSLSS Scores } \\
\hline & $n(\%)$ & $M(\mathrm{SD})$ & Minimum-Maximum \\
\hline \multicolumn{4}{|l|}{ Age } \\
\hline 11 & $102(23 \%)$ & $30.47(4.01)$ & $16-35$ \\
\hline 12 & $58(14 \%)$ & $30.01(3.75)$ & $16-35$ \\
\hline 13 & $57(13 \%)$ & $29.32(3.82)$ & $21-35$ \\
\hline 14 & $49(11 \%)$ & $29.57(4.49)$ & $14-35$ \\
\hline 15 & $43(10 \%)$ & $29.37(5.34)$ & $11-35$ \\
\hline 16 & $57(13 \%)$ & $29.77(4.41)$ & $18-35$ \\
\hline 17 & $68(16 \%)$ & $29.50(4.32)$ & $18-35$ \\
\hline \multicolumn{4}{|l|}{ Gender } \\
\hline Female & $191(44 \%)$ & $29.60(4.19)$ & $14-35$ \\
\hline Male & $243(56 \%)$ & $29.96(4.29)$ & $11-35$ \\
\hline \multicolumn{4}{|l|}{ Condition } \\
\hline Cerebral palsy & $151(35 \%)$ & $29.86(4.05)$ & $16-35$ \\
\hline Acquired brain injury & $59(14 \%)$ & $29.50(4.30)$ & $18-35$ \\
\hline Communication/cleft lip-palate & $41(11 \%)$ & $30.21(4.66)$ & $11-35$ \\
\hline Spina bifida & $36(8 \%)$ & $27.75(4.95)$ & $17-35$ \\
\hline Autism spectrum disorder & $35(7 \%)$ & $29.94(3.59)$ & $16-35$ \\
\hline Developmental delay & $29(6 \%)$ & $30.51(3.70)$ & $22-35$ \\
\hline Amputation & $18(4 \%)$ & $31.88(2.49)$ & $26-35$ \\
\hline Other & $65(15 \%)$ & $29.84(4.61)$ & $14-35$ \\
\hline
\end{tabular}

Sample $(n=434)$

the condition groups. Youth with an amputated limb reported significantly higher SLSS scores than those with autism spectrum disorder $(p<0.05)$.

\subsection{Internal Consistency and Scale Structure Analyses}

The internal consistency of the SLSS and BMSLSS items for both the youth and parent report total score was acceptable to good $(\alpha=0.79$ and 0.86 and $\alpha=0.73$ and 0.81 respectively). In the principal components analyses for the BMSLSS, a one-factor solution with an eigenvalue greater than one was identified for both the youth and parent version and contributed $48 \%$ and $58 \%$ of the variance, respectively. However, in the case of the SLSS, a two-factor solution was identified for both the youth and parent versions. In both versions, all five positively worded items fell into the first factor, accounting for $41 \%$ of the variance in the youth version, and $47 \%$ in the parent version. The two negatively worded items comprised the second factor for both versions of the SLSS, contributing approximately one quarter of the variance in both cases. See Tables 3 and 4 for further factor analyses results for the SLSS and the BMSLSS youth and parent reports respectively.

Additional analyses were conducted to assess the reliability and factor structure of the SLSS when the negatively worded items were removed. Cronbach's alpha improved for both the youth and parent versions of the SLSS ( $\alpha=0.82$ and 0.88 respectively), and a one-factor structure was indicated, accounting for $61 \%$ of the variance in the youth version, and $69 \%$ in the parent version. 
Table 3 Factor analyses for BMSLSS youth and parent reports

\begin{tabular}{|c|c|c|c|}
\hline & BMSLSS items & $\begin{array}{l}\text { Youth } \\
\text { Factor loadings }\end{array}$ & $\begin{array}{l}\text { Parent } \\
\text { Factor loadings }\end{array}$ \\
\hline 1. & $\begin{array}{l}\text { Satisfaction with my family life } \\
\text { Satisfaction with his/her life }\end{array}$ & 0.753 & 0.794 \\
\hline 2. & $\begin{array}{l}\text { Satisfaction with my friendships } \\
\text { Satisfaction with his/her friendships }\end{array}$ & 0.641 & 0.685 \\
\hline 3. & $\begin{array}{l}\text { Satisfaction with my school experience } \\
\text { Satisfaction with his/her school experience }\end{array}$ & 0.718 & 0.781 \\
\hline 4. & $\begin{array}{l}\text { Satisfaction with myself } \\
\text { Satisfaction with his/herself }\end{array}$ & 0.728 & 0.850 \\
\hline \multirow[t]{2}{*}{5.} & $\begin{array}{l}\text { Satisfaction with where I live } \\
\text { Satisfaction where he/she lives }\end{array}$ & 0.628 & 0.685 \\
\hline & Variance explained & $48 \%$ & $58 \%$ \\
\hline
\end{tabular}

Table 4 Factor analyses for SLSS youth and parent reports

\begin{tabular}{|c|c|c|c|c|c|}
\hline & \multirow[t]{2}{*}{ SLSS items } & \multicolumn{2}{|l|}{ Youth } & \multicolumn{2}{|l|}{ Parent } \\
\hline & & $\begin{array}{l}\text { Factor } 1 \\
\text { loadings }\end{array}$ & $\begin{array}{l}\text { Factor } 2 \\
\text { loadings }\end{array}$ & $\begin{array}{l}\text { Factor } 1 \\
\text { loadings }\end{array}$ & $\begin{array}{l}\text { Factor } 2 \\
\text { loadings }\end{array}$ \\
\hline 1. & $\begin{array}{l}\text { My life is going well } \\
\text { My child feels his/her life is going well }\end{array}$ & 0.778 & 0.266 & 0.832 & 0.240 \\
\hline 2. & $\begin{array}{l}\text { My life is just right } \\
\text { My child feels his/her life is just right }\end{array}$ & 0.777 & 0.319 & 0.830 & 0.187 \\
\hline 3. & $\begin{array}{l}\text { I would like to change things in my life } \\
\text { My child would like to change things } \\
\text { in his/her life }\end{array}$ & 0.155 & 0.845 & 0.155 & 0.904 \\
\hline 4. & $\begin{array}{l}\text { I wish I had a different kind of life } \\
\text { My child wishes he/she had a different } \\
\text { kind of life }\end{array}$ & 0.215 & 0.812 & 0.338 & 0.825 \\
\hline 5. & $\begin{array}{l}\text { I have a good life } \\
\text { My child feels he/she has a good life }\end{array}$ & 0.787 & 0.249 & 0.831 & 0.241 \\
\hline 6. & $\begin{array}{l}\text { I have what I want in life } \\
\text { My child feels he/she has what he/she } \\
\text { wants in life }\end{array}$ & 0.725 & 0.194 & 0.815 & 0.159 \\
\hline 7. & $\begin{array}{l}\text { My life is better than most kids } \\
\text { My child feels his/her life is better } \\
\text { than most kids }\end{array}$ & 0.687 & -0.012 & 0.665 & 0.308 \\
\hline & $\begin{array}{l}\text { Variance explained (total }=65 \% \text {-youth } \\
\text { report; } 72 \% \text {-parent report) }\end{array}$ & $41 \%$ & $24 \%$ & $47 \%$ & $25 \%$ \\
\hline
\end{tabular}

\subsection{Convergent Validity Between the SLSS and BLMSS Youth and Parent Reports}

The total scores for the SLSS and BMSLSS youth report total scores were highly correlated $(r=0.64, p<.0001)$ with each other. Likewise, the SLSS and BMSLSS parent report total scores were highly correlated $(r=0.69, \mathrm{p}<.0001)$. 


\subsection{Comparative Analyses for Youth and Parent Reports}

SLSS and BMSLSS mean youth total scores $(M=32.83, \mathrm{SD}=6.57 ; M=29.80$, $\mathrm{SD}=4.25$ respectively) were compared to SLSS and BMSLSS mean parent total scores $(M=29.25, \mathrm{SD}=6.62 ; M=27.24, \mathrm{SD}=4.55$ respectively $) . \mathrm{ICC}$ analysis indicated moderate agreement between youth and parent reports for both SLSS and the BMSLSS ( $\mathrm{ICC}=0.59,95 \% \mathrm{CI}=0.34$ to $0.50 ; \mathrm{ICC}=0.51,95 \% \mathrm{CI}=0.41$ to 0.60 respectively) and the $t$ test analyses showed that both the youth SLSS and BMSLSS scores were significantly higher than the parent scores $(t=10.40, p<0.0001 ; t=10.62, p<0.0001$ respectively). Youth and parent scores on SLSS and BMSLSS individual items were also compared. ICC analysis indicated fair to moderate agreement between youth and parent reports for individual SLSS items and moderate agreement between youth and parent reports for individual BMSLSS items. $t$ test analyses showed that youth scores on all individual items for both the SLSS and BMSLSS scores were significantly higher than the parent scores (see Tables 5, 6).

\section{Discussion}

This paper is the first to assess the psychometric properties of both the SLSS and the BMSLSS using a sample of youth with chronic conditions. Moreover, it is the first to compare the ratings of these youth report measures of PQOL with parent proxy versions.

This research provides evidence of the internal consistency and factor structure of the BMSLSS youth and parent reports when used with youth with chronic conditions. In addition, the one-factor solution found for the BMSLSS reflects the findings of other studies based on the general population (Funk et al. 2006; Seligson et al. 2005). Evidence of internal consistency was also indicated for the youth and parent reports of the SLSS. The two-factor structure of the SLSS youth and parent reports, however, differed from the onefactor structure that has been found consistently with normative samples of children and youth (Dew and Huebner 1994; Gilman and Huebner 1997). The first factor of the SLSS was comprised of five positively worded items, whereas the second factor included two negatively worded items.

Similar results have been found when assessing the factor structure of other measures of life satisfaction when used with youth with emotional difficulties or cognitive limitations (Griffin and Huebner 2000; Sawatzky et al. 2009). Research has indicated that some children have problems responding to negatively worded items (Marsh 1986). Huebner

Table 5 Comparative analyses for individual BMSLSS items on youth and parent reports

\begin{tabular}{|c|c|c|c|c|c|c|c|c|c|}
\hline \multirow[t]{2}{*}{ Item } & \multicolumn{2}{|c|}{ Youth } & \multicolumn{2}{|c|}{ Parent } & \multirow[t]{2}{*}{$t$} & \multirow[t]{2}{*}{$p$} & \multirow[t]{2}{*}{ ICC } & \multicolumn{2}{|c|}{$95 \% \mathrm{CI}$} \\
\hline & M & SD & M & SD & & & & $L L$ & $U L$ \\
\hline 1. & 6.17 & 1.11 & 5.70 & 1.08 & 7.33 & 0.0001 & 0.42 & 0.30 & 0.52 \\
\hline 2. & 6.08 & 1.09 & 5.22 & 1.32 & 12.13 & 0.0001 & 0.42 & 0.30 & 0.52 \\
\hline 3. & 5.54 & 1.39 & 5.22 & 1.33 & 4.19 & 0.0001 & 0.49 & 0.38 & 0.58 \\
\hline 4. & 6.02 & 1.24 & 5.34 & 1.18 & 9.73 & 0.0001 & 0.44 & 0.32 & 0.53 \\
\hline 5. & 6.02 & 1.25 & 5.76 & 1.09 & 4.00 & 0.0001 & 0.46 & 0.35 & 0.55 \\
\hline
\end{tabular}

$C I$ confidence interval, $L L$ lower limit, $U L$ upper limit 
Table 6 Comparative analyses for individual SLSS items on youth and parent reports

\begin{tabular}{|c|c|c|c|c|c|c|c|c|c|}
\hline \multirow[t]{2}{*}{ Item } & \multicolumn{2}{|c|}{ Youth } & \multicolumn{2}{|c|}{ Parent } & \multirow[t]{2}{*}{$t$} & \multirow[t]{2}{*}{$p$} & \multirow[t]{2}{*}{ ICC } & \multicolumn{2}{|c|}{$95 \% \mathrm{CI}$} \\
\hline & M & SD & M & SD & & & & $L L$ & $U L$ \\
\hline 1. & 5.33 & 0.98 & 4.96 & 1.07 & 6.80 & 0.0001 & 0.57 & 0.48 & 0.65 \\
\hline 2. & 5.12 & 1.08 & 4.51 & 1.25 & 9.08 & 0.0001 & 0.45 & 0.33 & 0.54 \\
\hline 3. & 3.18 & 1.89 & 2.66 & 1.47 & 4.80 & 0.0001 & 0.22 & 0.06 & 0.36 \\
\hline 4. & 4.29 & 1.87 & 3.41 & 1.66 & 7.90 & 0.0001 & 0.28 & 0.13 & 0.42 \\
\hline 5. & 5.46 & 0.98 & 4.94 & 1.00 & 9.28 & 0.0001 & 0.47 & 0.36 & 0.56 \\
\hline 6. & 4.97 & 1.24 & 4.63 & 1.08 & 4.76 & 0.0001 & 0.36 & 0.23 & 0.48 \\
\hline 7. & 4.48 & 1.46 & 4.22 & 1.30 & 3.22 & 0.001 & 0.41 & 0.29 & 0.51 \\
\hline
\end{tabular}

$C I$ confidence interval, $L L$ lower limit, $U L$ upper limit

et al. (2012) suggest that these findings may reflect cognitive-developmental limitations in youth. However, since both the youth and parent versions of the SLSS had a two-factor structure, one consisting of positive items and one of negative items, another possible explanation is that this phenomenon might be due to method effects (Marsh 1996).

That being said, since a one factor structure has been found consistently when the SLSS has been tested on normative youth samples, there might possibly be something different occurring with this sample of youth with chronic conditions. One speculation might be that the second factor that consists of one negatively worded question about desire for a different kind of life and another about desire to make changes in life may be reflective of a real construct capturing youths' desire for life change related to their chronic conditions, as well as their parents' awareness of that desire. The desire for life change may be much more salient for youth with chronic conditions than those without chronic conditions, especially during adolescence, as these youth become more aware of friendship issues, condition-related responsibilities, desire for autonomy from parents, attitudes of others, and barriers to school and community participation (Blum 1992; Groce 2004).

The Multidimensional Students' Life Satisfaction Scale (MSLSS) (Huebner 1994), the long version of the BMSLSS has been tested on a sample of 844 middle school students when the negatively-worded items and other problematic items were removed, and acceptable reliability coefficients and fit across several indices have been found (Huebner et al. 2012). Likewise, in the current study, when the negatively worded items in the SLSS were removed, Cronbach's alpha improved for both the youth and parent versions and a one-factor structure was indicated for both versions. When using the SLSS with youth with chronic conditions and their parents, one composite measure that consist of the five positively worded items could be used to capture the construct of overall life satisfaction, and a separate summed index could be created using the two negatively worded items to capture the construct of desire for life change. However, further testing of the SLSS on other samples of youth with chronic conditions is advisable. Confirmatory factor analysis would be a useful approach to use in future work to determine whether the two-factor solution of the SLSS found in this study is meaningful or an artifact (Marsh 1996).

This research provides initial evidence that the two PQOL measures are suitable to use with youth who have chronic conditions. Means scores for both the SLSS and the BMSLSS are in line with what has been found in the general population of similar aged youth (Funk et al. 2006; Gilman and Huebner 1997). The associations between youth life satisfaction reports using the SLSS and the BMSLSS and age and gender did not reach statistical 
significance These findings are also reflective of past studies using normative samples that have found demographic variables to have little relationship to PQOL (Dew and Huebner 1994; Funk et al. 2006; Gilman and Huebner 1997; Huebner and Alderman 1993).

Past studies have found that youth with chronic conditions often report their QOL to be similar to youth without chronic conditions (e.g., Majnemer et al. 2007), supporting the assertion that PQOL is representative of more than health status. Indeed, the associations between youth life satisfaction reports using the SLSS and the BMSLSS and chronic condition were not statistically significant. However, differences in SLSS reports between youth with an amputated limb and youth with autism spectrum disorder did approach statistical significance. It may therefore be of benefit for future research to look more closely at these associations using larger samples of each type of condition, and at the factors that might lead groups of children with physical conditions to report different levels of PQOL compared to youth with mental and behavioral conditions.

This study sample was composed of youth with the type of chronic conditions for which rehabilitation services are provided. This work provides an initial indication that, although the SLSS and the BMSLSS were originally created for use with children in the general population, they may also be used reliably and validly (with some modification to the SLSS) in an interview format with youth with cerebral palsy, acquired brain injury, and other chronic conditions, such as spina bifida or communication disorders given that youth have the cognitive ability to understand the questions and response options.

Findings indicated moderate inter-rater agreement between youth and parents for the total scores on the SLSS and the BMSLSS. At the same time, significant mean differences were found between youth and parent reports for the two measures, indicating that youth view their PQOL differently than their parents. This finding reflects other studies that youth with chronic conditions report higher scores with respect to their HQOL/QOL (Morrow et al. 2012; Upton et al. 2008; White-Koning et al. 2007).

Several possibilities may contribute to youth reporting a higher PQOL: (a) youth may have more accurate view of their life quality; (b) youth may be more satisfied than their parents realize; or (c) response shift bias (i.e., youth could be idealizing their life quality to the interviewer). Parents complete the study questionnaire independently, whereas the youth completes the questionnaire as part of an interview. Youth may be less likely to tell another person that they are dissatisfied with life. Efforts were made to minimize response shift bias in this study by training interviewers to conduct the interviews using a standardized protocol.

Regardless of differences between reports, each reflect the individual's beliefs about the youth's well being (Upton et al. 2008). Moreover, both the youth and the parent report can provide its own contribution to an understanding of a youths' PQOL (Parsons et al. 1999). The SLSS and BMSLSS youth and parent versions appear to be measuring PQOL similarly enough to warrant use of the youth report alone when youth perspectives are of primary interest, parent report when youth reports are not possible (i.e., due to a youth's cognitive limitations), or parallel use when nuances between parent and youth viewpoints are important to understand.

Ceiling effects were found for SLSS and BMSLSS in only 7 and $11 \%$ of individuals, respectively, indicating that this is not an issue with these measures when used with youth with chronic conditions. Convergent validity of both the youth and parent versions of the SLSS and the BMSLSS was also indicated with this sample. 


\section{Conclusion, Limitations and Future Research Directions}

Research on indicators related to subjective child well being, including their perceptions of life quality/satisfaction is an emerging field that requires reliable and valid tools (BenArieh 2010; Fernandes et al. 2012). This study has provided preliminary psychometric evidence for using the SLSS and the BMSLSS in population-based research specifically involving youth who have chronic conditions. This research suggests that the youth selfreport and the parent proxy report version of the SLSS and the BMSLSS are promising measures for assessing PQOL of largely English speaking youth aged 11-17 with the types of chronic conditions for which rehabilitation services are provided.

Recommendations for further psychometric testing of the youth and parent report SLSS and the BMSLSS with larger, more heterogeneous samples of youth with chronic conditions includes: assessing test-retest reliability over a 1-2 week retest interval, further evaluating discriminant validity amongst youth with chronic conditions; further examining youth-parent agreement/mean differences; and further exploring the factor structure of the SLSS. In addition, the responsiveness to change of both the youth and parent report when used with this population of youth needs to be studied. Finally, as Topolski et al. (2004) point out, to advance the use of self-report QOL measures in population surveys of youth with and without chronic conditions, cognitive interview studies should be conducted to help understand what youth are thinking when they respond to questionnaires about life quality.

Acknowledgments This research is supported by a research grant (\#191232) from the Canadian Institutes of Health Research. Appreciation is extended to the youth, families, and staff at the various rehabilitation centers who participated in this research.

\section{References}

Alfonso, V., Allison, D., Rader, D., \& Gorman, B. (1996). The extended satisfaction with Life Scale: Development and psychometric properties. Social Indicators Research,38(3), 275-310.

Ben-Arieh, A. (2010). From child welfare to children well-being: The child indicators perspective. In S. B. Kamerman, S. Phipps \& A. Ben-Arieh (Eds.), From child welfare to child well-being, an international perspective on knowledge in the service of policy making (pp. 9-22). Dordrecht: Springer.

Bijleveld, C., van der Kamp, L., Mooijaart, A., van der Kloot, W., van der Leeden, R., \& van der Burg, E. (1998). Longitudinal data analysis: Designs, models, and methods. London: Sage.

Blum, R. W. (1992). Chronic illness and disability in adolescence. Journal of Adolescent Health,13(5), $364-368$.

Brantley, A., Huebner, E., \& Naagle, R. (2002). Multidimensional life satisfaction reports of adolescents with mild mental disabilities. Mental Retardation,40(4), 321-329.

Cummins, R., McCabe, M., Romeo, Y., \& Gullone, E. (1994). The Comprehensive Quality of Life Scale (ComQol): Instrument development and psychometric evaluation on college staff and students. Educational and Psychological Measurement,54(2), 372-382.

Davis, E., Waters, E., Mackinnon, A., Reddihough, D., Graham, H., Mehmet-Radji, O., et al. (2006). Paediatric quality of life instruments: A review of the impact of conceptual frameworks on outcomes. Developmental Medicine and Child Neurology,48(4), 311-318.

Dew, T., \& Huebner, E. (1994). Adolescents' perceived quality of life: An exploratory investigation. Journal of School Psychology,33(2), 185-199.

Diener, E., Emmons, R., Larsen, R., \& Griffin, S. (1985). The satisfaction with Life Scale. Journal of Personality Assessment,49(1), 71-75.

Eiser, C., \& Morse, R. (2001). Can parents rate their child's health-related quality of life? Results of a systematic review. Child: Care, Health and Development,10(4), 347-357. 
Feeny, D., Furlong, W., Boyle, M., \& Torrance, G. (1995). Multi-attribute health status classification systems: Health Utility Index. Pharmacoeconomics, 7(6), 490-502.

Feldman, B., Grundland, B., McCullough, L., \& Wright, V. (2000). Distinction of quality of life, health related quality of life, and health status in children referred for rheumatologic care. The Journal of Rheumatology,27, 226-233.

Fernandes, L., Mendes, A., \& Teixeira, C. (2012). A review essay on the measurement of child well-being. Social Indicators Research,106(2), 239-257.

Ferrans, C. (1996). Development of a conceptual model of quality of life. Scholarly Inquiry for Nursing Practice,10(3), 293-304.

Fogle, L., Huebner, E., \& Laughlin, J. (2002). The relationship between temperament and life satisfaction in early adolescence: Cognitive and behavioral mediation models. Journal of Happiness Studies,3(4), 372-392.

Funk, B., Huebner, E., \& Valois, R. (2006). Reliability and validity of a brief life satisfaction scale with a high school sample. Journal of Happiness Studies, 7(1), 41-54.

Gilligan, T., \& Huebner, E. (2007). Initial development and validation of the Multidimensional Students' Life Satisfaction Scale-Adolescent Version. Applied Research in Quality of Life,2(1), 1-16.

Gilman, R. (2001). The relationship between life satisfaction, social interest, and frequency of extracurricular activities among adolescent students. Journal of Youth and Adolescence,30(6), 749-767.

Gilman, R., \& Huebner, E. (1997). Children's reports of their life satisfaction: Convergence across raters, time, and response format. School Psychology International,18(3), 229-243.

Gilman, R., \& Huebner, E. (2003). A review of life satisfaction research with children and adolescents. School Psychology Quarterly, 18(2), 192-205.

Gortmaker, S., Walker, D., Weitzman, M., \& Sobol, A. (1990). Chronic conditions, socioeconomic risks, and behavioral problems in children and adolescents. Pediatrics, 85(3), 267-276.

Graham, P., Stevenson, J., \& Flynn, D. (1997). A new measure of health-related quality of life for children: Preliminary findings. Psychology and Health,12(5), 655-665.

Griffin, M., \& Huebner, E. (2000). Multidimensional life satisfaction reports of middle school students with serious emotional disturbance. Journal of Psychoeducational Assessment,18(2), 111-124.

Groce, N. (2004). Adolescents and youth with disability: Issues and challenges. Asia Pacific Disability Rehabilitation Journal,15(2), 13-32.

Helders, P. (2001). To be and to become: The changing focus of developmental paediatrics. Disability and Rehabilitation,23(13), 583-585.

Huebner, E. (1991a). Initial development of the Students' Life Satisfaction Scale. School Psychology International,12(3), 231-240.

Huebner, E. (1991b). Further validation of the Students' Life Satisfaction Scale: The independence of satisfaction and affect ratings. Journal of Psychoeducational Assessment,9(4), 363-368.

Huebner, E. (1994). Preliminary development and validation of a multidimensional life satisfaction scale for children. Psychological Assessment,6(2), 149-158.

Huebner, E., \& Alderman, G. (1993). Convergent and discriminant validation of a children's life satisfaction scale: Its relationship to self- and teacher-reported psychological problems and school functioning. Social Indicators Research,30(1), 71-82.

Huebner, E., Drane, J., \& Valois, R. (2000). Levels and demographic correlates of adolescent life satisfaction reports. School Psychology International,21(3), 281-292.

Huebner, E., Gilman, R., \& Suldo, S. (2007). Assessing quality of life in children and youth. In S. Smith \& L. Handler (Eds.), The clinical assessment of children and adolescents: A practioner's handbook (pp. 349-366). New York, NY: Taylor and Francis Group.

Huebner, E., Suldo, S., Smith, \& McKnight, C. (2004). Life satisfaction in children and youth: Empirical foundations and implications for school psychologists. Psychology in Schools,41(1), 81-93.

Huebner, E., Zullig, K., \& Saha, R. (2012). Factor structure and reliability of an abbreviated version of the Multidimensional Students' Life Satisfaction Scale. Child Indicators Research. Advance online publication. doi:10.1007/s12187-012-9140-z.

King, S., Schwellnus, H., Russell, D., Shapiro, L., \& Aboelele, O. (2005). Assessing quality of life of children and youth with disabilities: A review of available measures (Keeping Current \#01-2006). Hamilton, Ontario: McMaster University, CanChild: Centre for Childhood Disability Research.

Law, M., Finkleman, S., Hurley, P., Rosenbaum, P., King, S., King, G., et al. (2004). Participation of children with physical disabilities: Relationships with diagnosis, physical function, and demographic variables. Scandinavian Journal of Occupational Therapy, 11(4), 156-162.

Livingstone, M., Rosenbaum, P., Russell, D., \& Palisano, R. (2007). Quality of life among adolescents with cerebral palsy: What does the literature tell us? Developmental Medicine and Child Neurology,49(4), 225-231. 
Majnemer, A., Shevell, M., Rosenbaum, P., Law, M., \& Poulin, C. (2007). Determinants of life quality in school-aged children with cerebral palsy. The Journal of Pediatrics, 151(5), 470-475.

Marsh, H. (1986). Negative item bias in rating scales for preadolescent children: A cognitive-developmental phenomenon. Developmental Psychology,22(1), 37-49.

Marsh, H. (1996). Positive and negative global self-esteem: A substantively meaningful distinction or artifactors? Journal of Personality and Social Psychology,70(4), 810-819.

McCullough, G., \& Huebner, E. (2003). Life satisfaction reports of adolescents with learning disabilities and normally achieving adolescents. Journal of Psychoeducational Assessment,21(4), 311-324.

McDougall, J., Wright, V., Miller, L., \& Nichols, M. (2012). Evaluation of two measures of perceived quality of life when used with youth with chronic conditions [Abstract]. Developmental Medicine and Child Neurology,54(Supp. 6), 34-35.

McDougall, J., Wright, V., \& Rosenbaum, P. (2010). The ICF Model of Functioning and Disability: Incorporating quality of life and human development. Developmental Neurorehabilitation,13(3), 204-211.

McDougall, J., Wright, V., Schmidt, J., Miller, L., \& Lowry, K. (2011). Applying the ICF Framework to study changes in quality of life for youth with chronic conditions. Developmental Neurorehabilitation, 14(1), 41-53.

Moons, P., Werner, B., \& De Geest, S. (2006). Critique on the conceptualization of quality of life: A review and evaluation of different conceptual approaches. International Journal of Nursing Studies,43(7), 891-901.

Morrow, A., Hayen, A., Quine, S., Scheinberg, A., \& Craig, J. (2012). A comparison of doctors', parents', and children's reports of health states and health-related quality of life in children with chronic conditions. Child: Care, Health, and Development,38(2), 186-195.

Parsons, S., Barlow, S., Levy, S., Supran, S., \& Kaplan, S. (1999). Health-related quality of life in paediatric bone marrow transplant survivors: According to whom? International Journal of Cancer Supplement, 12(1), 46-51.

Pless, I., \& Perrin, J. (1985). Issues common to a variety of illnesses. In N. Hobbs \& J. M. Perrin (Eds.), Issues in the care of children with chronic illness: A sourcebook on problems, services, and policies (pp. 41-60). San Francisco: Jossey-Bass.

Proctor, C., Linley, A., \& Maltby, J. (2009a). Youth life satisfaction: A review of the literature. Journal of Happiness Studies, 10(5), 583-630.

Proctor, C., Linley, A., \& Maltby, J. (2009b). Youth life satisfaction measures: A review. The Journal of Positive Psychology,4(2), 128-144.

Sawatzky, R., Ratner, P., Johnson, J., Kopec, J., \& Zumbo, B. (2009). Sample heterogeneity and the measurement structure of the Multidimensional Students' Life Satisfaction Scale. Social Indicators Research,94(1), 273-296.

Seligson, J., Huebner, E., \& Valois, R. (2003). Preliminary validation of the Brief Multidimensional Students' Life Satisfaction Scale (BMSLSS). Social Indicators Research,61(2), 121-145.

Seligson, J., Huebner, E., \& Valois, R. (2005). An investigation of a brief life satisfaction scale with elementary school children. Social Indicators Research,73(3), 355-374.

Smith, D., Adelman, H., Nelson, P., \& Taylor, L. (1987). Students' perceptions of control at school and problem behavior and attitudes. Journal of School Psychology,25(2), 167-176.

Stein, R., \& Jessop, D. (1984). Relationship between health status and psychological adjustment among children with chronic conditions. Pediatrics,73(2), 169-174.

Stein, R., \& Jessop, D. (1990). Functional Status II (R): A measure of child health status. Medical Care,28(11), 1041-1055.

Terry, T., \& Huebner, E. (1995). The relationship between self-concept and life satisfaction in children. Social Indicators Research,35(1), 39-52.

Topolski, T., Edwards, T., \& Patrick, D. (2004). Toward youth self-report of health and quality of life in population monitoring. Ambulatory Pediatrics,4(4), 387-394.

Upton, P., Lawford, J., \& Eiser, C. (2008). Parent-child agreement across child health-related quality of life instruments: A review of the literature. Quality of Life Research,17(6), 895-913.

Valois, R., Zullig, K., Huebner, E., \& Drane, J. (2001). Relationships between life satisfaction and violent behaviors among adolescents. American Journal of Health \& Behavior, 25(4), 353-366.

Vassar, M., \& Hale, W. (2007). Reliability reporting practices in youth life satisfaction research. Social Indicators Research,83(3), 487-496.

Wallander, J., Schmitt, M., \& Koot, H. (2001). Quality of life measurement in children and adolescence: Issues, instruments, and applications. Journal of Clinical Psychology,57(4), 571-585.

Wallander, J., \& Varni, J. (1989). Social support and adjustment in chronically ill and handicapped children. American Journal of Community Psychology, 17(2), 185-201. 
White-Koning, M., Arnaud, C., Dickinson, H., Thyen, U., Beckung, E., Fauconnier, J., et al. (2007). Determinants of child-parent agreement in quality of life reports: A European study of children with cerebral palsy. Pediatrics,120(4), e804-e814.

Zhan, L. (1992). Quality of life: Conceptual and measurement issues. Journal of Advanced Nursing, 17(7), $795-800$.

Zullig, K., Huebner, E., Gilman, R., Patton, J., \& Murray, K. (2005). Validation of the Brief Multidimensional Students' Life Satisfaction Scale among college students. American Journal of Health Behavior,29(3), 206-214. 